Donkervoort, M., Dekker, J., Ende, E. van den, Stehmann-Saris, J.C., Deelman, B.G.

Prevalence of apraxie among patients with a first left hemisphere stroke in rehabilitation centres and nursing homes.

Clinical Rehabilitation: 14, 2000, nr. 2, p. p. 130-136

\begin{tabular}{|l|l|}
\hline $\begin{array}{l}\text { Postprint } \\
\text { Version }\end{array}$ & 1.0 \\
\hline Journal website & http://www.ingentaconnect.com \\
\hline Pubmed link & $\begin{array}{l}\text { http://www.ncbi.nlm.nih.gov/entrez/query.fcgi?cmd=Retrieve\&db=pubmed\&dopt=Abst } \\
\text { ract\&list_uids=10763789\&query_hl=56\&itool=pubmed_docsum }\end{array}$ \\
\hline DOI & \\
\hline
\end{tabular}

Address for correspondence: M Donkervoort, NIVEL/ Netherlands Institute of Primary Health Care, PO Box 1568, 3500 BN Utrecht, The Netherlands. e-mail: M.Donkervoort@nivel.nl

\title{
Prevalence of apraxia among patients with a first left hemisphere stroke in rehabilitation centres and nursing homes
}

M DONKERVOORT Netherlands Institute of Primary Health Care, Utrecht, J DEKKER Netherlands Institute of Primary Health Care and Vrije Universiteit Amsterdam, E VAN DEN ENDE Netherlands Institute of Primary Health Care, Utrecht, JC STEHMANN-SARIS School for Occupational Therapy, Amsterdam, BG DEELMAN University of Groningen, Groningen, The Netherlands

Objective: To investigate the prevalence of apraxia in patients with a first left hemisphere stroke.

Subjects: Left hemisphere stroke patients staying at an inpatient care unit of a rehabilitation centre or nursing home and receiving occupational therapy $(n=600)$.

Measures: A short questionnaire on general patient characteristics and stroke-related aspects was completed by occupational therapists for every left hemisphere stroke patient they treated. A diagnosis of apraxia or nonapraxia was made in every patient, on the basis of a set of clinical criteria.

Results: The prevalence of apraxia among 492 first left hemisphere stroke patients in rehabilitation centres was 28\% (96/338) and in nursing homes 37\% (57/154). No relationship was found between the prevalence of apraxia and age, gender or type of stroke (haemorrhage or infarct).

Conclusions: This study shows that approximately one-third of left hemisphere stroke patients has apraxia.

\section{INTRODUCTION}

Apraxia is defined as the inability to carry out learned and purposeful activities. This inability cannot be explained by primary motor or sensory impairments, or deficits in motivation, memory or comprehension. ${ }^{1,2}$ Apraxia can lead to severe disabilities in daily living activities. ${ }^{2-4}$

Similar to aphasia, apraxia appears to be one of the more frequent impairments after a left hemisphere stroke. ${ }^{3,5}$ However, little is known on the exact prevalence of apraxia. A computerized search in several reference databases (MEDLINE, PSYCHLIT, EMBASE and CINAHL) in combination with intensive reference searching yielded 10 studies. $^{5-14}$ These studies are summarized in Table 1. 


\section{[ TABLE 1 ]}

The occurrence of apraxia after brain damage was first mentioned by Liepmann in the early twentieth century. ${ }^{6}$ In the late 1960s and throughout the 1980s some studies appeared which focused on neuroanatomical correlates of apraxia, but also addressed the prevalence of apraxia. Eight of the 10 studies listed in Table 1 are from two collaborating Italian research groups (University of Milan ${ }^{5,7-}$ 9,13 and the University of Modena ${ }^{10,11,13,14}$ ). It is unclear to what extent data from these studies concern overlapping patient groups.

From Table 1 it is apparent that in all studies the patient groups were of relatively moderate size, ranging from 40 to 177 patients. Therefore, the reliability of the prevalence estimates is limited. The patients in these studies were mainly recruited at the neurological wards of the university hospitals. In several studies the patient group was partly recruited from an outpatient aphasia/speech unit. ${ }^{5,8-10,13}$ This implies that the patient groups were not unselected: because of a strong association between aphasia and apraxia, the prevalence of apraxia might be overestimated. The most common aetiology in the different studies was stroke (61-100\%). In only four studies the patient group consisted exclusively of stroke patients. ${ }^{5,9,12,13}$ In the other seven studies the composition of the patient groups was unclear or heterogeneous. ${ }^{6-8,10-12,14}$ Trauma and tumour are the other aetiologies mentioned.

The studies found in the literature demonstrated that the prevalence of apraxia differs enormously in right and left hemisphere-damaged patients. In left hemisphere brain-damaged patients, the prevalence of apraxia ranged from $28 \%$ to $57 \%$ (median score $45 \%$ ). In the six studies that addressed the prevalence of apraxia in right hemisphere brain-damaged patients, the prevalence of apraxia ranged from $0 \%$ to $34 \%$ (median score $8 \%$ ). Thus, apraxia seems to be strongly associated with left hemisphere stroke, and only occurs infrequently with right hemisphere stroke.

In conclusion, the number of studies on the prevalence of apraxia is small; several of these studies concerned heterogeneous or selected patient groups, reducing the number of valid studies even more. Therefore, the aim of the present study was to investigate the prevalence of apraxia among patients with a first left hemisphere stroke hospitalized in rehabilitation centres and nursing homes.

\section{METHOD}

\section{Study design}

The data for this study have been accumulated during the recruitment process of a clinical trial on the effect of strategy training in left hemisphere stroke patients with apraxia. A convenience sample of 48 institutes (14 rehabilitation centres and 34 nursing homes) in the Netherlands participated in the study. In these 48 institutes all patients who (a) were staying at an inpatient department, (b) were referred for occupational therapy, and (c) had a left hemisphere stroke, were screened for the presence of apraxia. Patients with a recurrent stroke were excluded from this study. The period of recruitment was from November 1996 to August 1998.

\section{Assessment}

Occupational therapists completed a questionnaire, providing information on the following topics:

1. General patient characteristics: date of birth and gender.

2. Stroke-related aspects: date of stroke and type of stroke (haemorrhage/infarction and first/recurrent).

3. Diagnosis of apraxia (yes/no).

Because there are no standardized tests of apraxia, a clinical diagnosis was used. ${ }^{2}$ The patient was diagnosed as apraxic if (a) the patient showed the inability (or restriction in the ability) to carry out purposeful activities and (b) this inability was not the result of a primary motor or sensory impairment, or a deficit of comprehension or motivation. ${ }^{1}$ Patients were diagnosed as apraxic or nonapraxic by their treating medical team. This medical team consisted of the attending physician and occupational therapist; representatives of other disciplines (e.g. a neuropsychologist, physical therapist or speech therapist) could participate in the medical team. The diagnosis of apraxia was based on a combination of observations of daily activities, imitation tasks, and use of object tasks which were part of the standard clinical procedure. 
Donkervoort, M., Dekker, J., Ende, E. van den, Stehmann-Saris, J.C., Deelman, B.G.

Prevalence of apraxie among patients with a first left hemisphere stroke in rehabilitation centres and nursing homes.

Clinical Rehabilitation: 14, 2000, nr. 2, p. p. 130-136

\section{Statistical analysis}

The prevalence of apraxia was calculated separately for rehabilitation centres and nursing homes, because there is reason to expect that patients in these two settings differ with regard to specific patient characteristics (e.g. age, gender and rehabilitation prospects). Differences in frequencies were tested by means of a chi-square test. A $t$-test was used to investigate age differences. For all tests the significance level was set to 0.01. Analyses were performed using SPSS-X.

\section{RESULTS}

\section{Patients}

Over a period of 22 months (November 1996 to August 1998) 600 patients were screened. A total of 108 patients from these 600 were excluded because they had a recurrent stroke. In these cases it was unclear if the apraxia resulted from the first or a recurrent stroke. Table 2 summarizes the general characteristics of the remaining patients with a first left hemisphere stroke $(n=492)$. Approximately two-thirds of the population was recruited from rehabilitation centres $(n=338)$ and approximately one-third from nursing homes $(n=154)$. As can be seen in Table 2 the composition of these two patient groups was quite different. The mean age in the rehabilitation group was 59.8 years versus a mean age of 75.1 in the nursing home group. In the rehabilitation centres more male than female patients were included (60\% versus $40 \%$ ) while in the nursing homes it was just the opposite $(40 \%$ versus $60 \%)$.

\section{[ TABLE 2 ]}

The aetiology was found to be similar in both patient groups; approximately $60-70 \%$ of the patients has had a cerebral infarction and approximately $18 \%$ a cerebral haemorrhage.

\section{Prevalence of apraxia}

Table 3 shows the results with regard to the prevalence of apraxia. The prevalence of apraxia in the rehabilitation centre group was 28\% (95\% confidence interval (CI) 23-33\%). In the nursing home group the prevalence was 37\% (95\% CI 29-45\%). For 12 patients in the rehabilitation centres and 15 in the nursing homes the diagnosis of apraxia was uncertain. In the nursing home group relatively more patients were found to be apraxic compared to the rehabilitation group $(p<0.01)$; this comparison concerns patients with/without apraxia (patients with an uncertain diagnosis were excluded). The prevalence of apraxia in patients $(n=108)$ with a recurrent stroke was $30 \%(19 / 64)$ in the rehabilitation centres and 55\% (24/44) in the nursing homes (not in Table).

\section{[ TABLE 3 ]}

Next, the association between patient characteristics and the prevalence of apraxia was studied. Patients with an uncertain diagnosis were excluded from these analyses. The prevalence of apraxia was not associated with gender, age or type of stroke.

\section{CONCLUSION AND DISCUSSION}

The results of the present study show that the prevalence of apraxia is $28 \%$ in patients with a first left hemisphere stroke in rehabilitation centres and 37\% in nursing homes. The study did not show a relationship between patient characteristics and the prevalence of apraxia: no significant association was found with gender, age and type of stroke (haemorrhage or infarction).

The patients in the present study were recruited from rehabilitation centres and nursing homes. Thus, our study is not a population-based study. Assuming that the patients with less severe impairments are not admitted to a rehabilitation centre or nursing home, our data probably over- estimate the prevalence of apraxia in the population. However, in those patients who are referred to a rehabilitation centre or a nursing home the prevalence of apraxia appears to be rather high $(28 \%$ and $37 \%$ respectively). These prevalence rates are lower than those found in other studies on first left hemisphere stroke. ${ }^{5,9,13}$ In these studies, patients were recruited from neurological wards and aphasia units. Because there is a strong association between aphasia and apraxia, this has probably resulted in an overestimation of the prevalence of apraxia. 
Donkervoort, M., Dekker, J., Ende, E. van den, Stehmann-Saris, J.C., Deelman, B.G.

Prevalence of apraxie among patients with a first left hemisphere stroke in rehabilitation centres and nursing homes.

Clinical Rehabilitation: 14, 2000, nr. 2, p. p. 130-136

\section{[ FIGURE 1 ]}

In the absence of standardized tests, the diagnosis of apraxia necessarily had to rely on clinical judgement. The diagnosis of apraxia was made by the treating medical team, based on a clear definition of apraxia (see Method section). Of course one can question the validity of a clinical diagnosis. In this context, it should be mentioned that we have recently developed a test for apraxia, which can be used to objectify and support the clinical diagnosis of apraxia. ${ }^{15}$ This test was applied in a subgroup of 100 patients clinically diagnosed as apraxic: only seven patients did not meet the criterion for apraxia on this test. Thus, the clinical diagnosis of apraxia could be confirmed in almost all patients. On the other hand, the medical team could have missed certain cases of apraxia. We believe this is not very likely, because we urged the medical team to point out every single case of apraxia. For these reasons we tend to trust the validity of the clinical diagnosis of apraxia, as made by the medical team and based on a clear definition of apraxia.

The present study shows that apraxia occurs in about one-third of left hemisphere stroke patients. Although it may have a favourable prognosis in some cases, apraxia is frequently associated with severe disability. Thus, there is a need to increase research efforts on apraxia and its treatment.

\section{ACKNOWLEDGEMENTS}

This study is supported by the Netherlands Heart Foundation (95.009) and the Health Insurance Funds Council.

\section{REFERENCES}

1 De Renzi E. Apraxia. In: Boller F, Grafman J eds. Handbook of neuropsychology, Volume 2. Amsterdam: Elsevier Science Publisher, 1989: 245-63.

2 Rothi LJG, Heilman KM. Apraxia: the neuropsychology of action. East Sussex: Psychology Press, 1997.

3 Foundas AL, Henchey R, Gilmore RL, Fennell EB, Heilman KM. Apraxia during Wada testing. Neurology 1995; 45: 1379-83.

4 Bjorneby ER, Reinvang IR. Acquiring and maintaining self-care skills after stroke: The predictive value of apraxia. Scand J Rehabil Med 1985; 17: 75-80.

5 Basso A, Capitani E, Della Sala S, Laiacona M, Spinnler H. Ideomotor apraxia: a study of initial severity. Acta Neurol Scand 1987; 76: 142-46

6 Liepmann H. Drei Aufsatze aus dem Apraxiegebiet. Berlin: Karger, 1908.

7 Pieczuro A, Vignolo LA. Studio spermentale sull'aprassia ideomotoria. Sist Nerv 1967; 19: 131-43.

8 De Renzi E, Pieczuro A, Vignolo LA. Ideational apraxia: a quantitative study. Neuropsychologia 1968; 6: 41-52.

9 Basso A, Luzatti C, Spinnler H. Is ideomotor apraxia the outcome of damage to well-defined regions of the left hemisphere? J Neurol Neurosurg Psychiatry 1980; 43: 118-26.

10 De Renzi E, Motti F, Nichelli P. Imitating gestures; a quantitative approach to ideomotor apraxia. Arch Neurol 1980; 37: 6-10.

11 De Renzi E, Faglioni P, Sorgato P. Modality-specific and supramodal mechanisms of apraxia. Brain 1982; 105: 301-12.

12 Kertesz A, Ferro JM. Lesion size and location in ideomotor apraxia. Brain 1984; 107: 921-33.

13 Basso A, Faglioni $P$, Luzzatti C. Methods in neuroanatomical research and an experimental study of limb apraxia. In: Roy EA ed. Neuropsychological studies of apraxia and related disorders. Amsterdam: North-Holland, 1985: 179-202.

14 Barbieri C, De Renzi E. The executive and ideational components of apraxia. Cortex 1988; 24: $535-43$

15 Heugten CM van, Dekker J, Deelman BG, Stehmann-Saris JC, Kinebanian A. A diagnostic test for apraxia in stroke patients: internal consistency and diagnostic value. Clin Neuropsychol 1999; 13: 111. 
Donkervoort, M., Dekker, J., Ende, E. van den, Stehmann-Saris, J.C., Deelman, B.G.

Prevalence of apraxie among patients with a first left hemisphere stroke in rehabilitation centres and nursing homes.

Clinical Rehabilitation: 14, 2000, nr. 2, p. p. 130-136

\section{TABLES AND FIGURE}

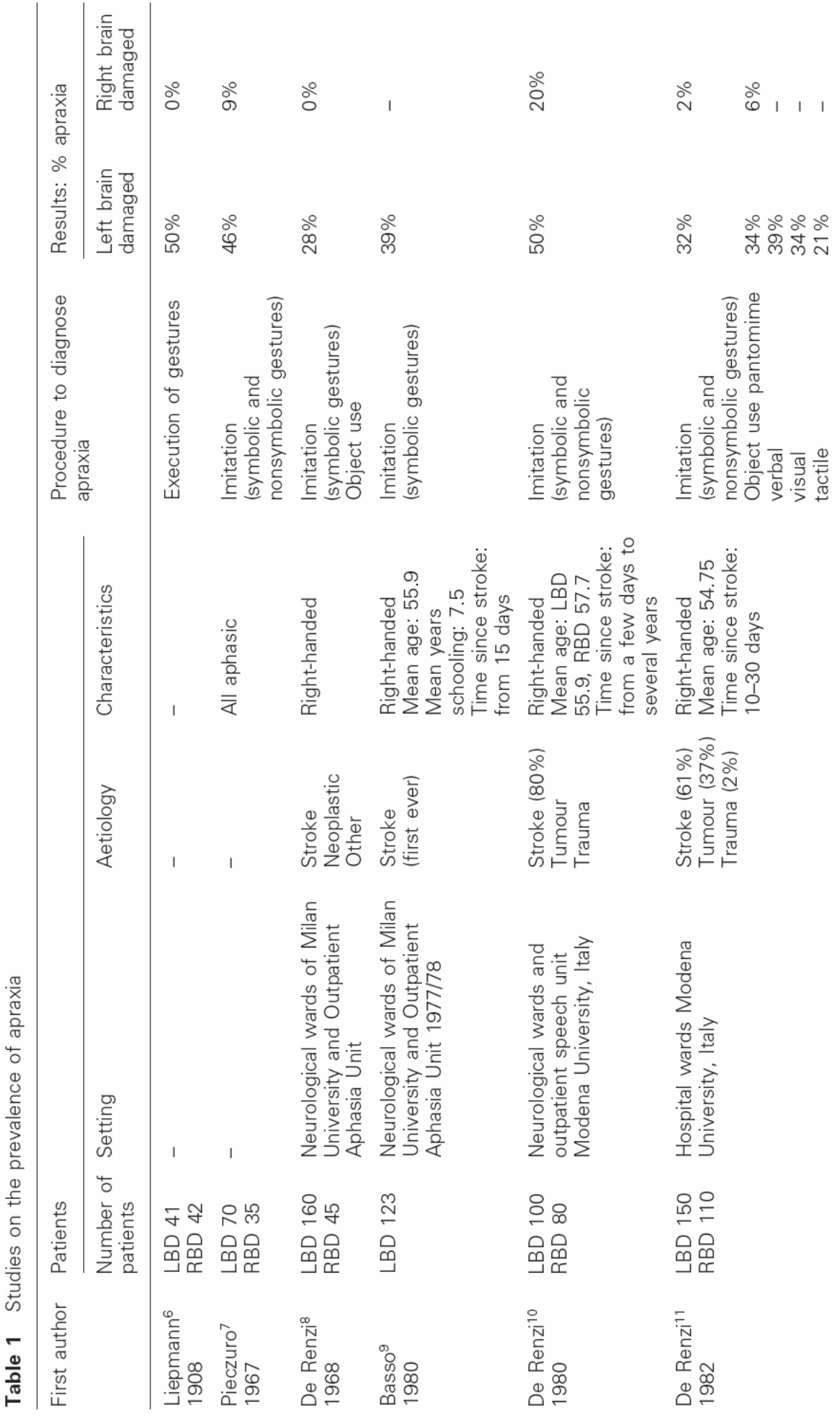


Donkervoort, M., Dekker, J., Ende, E. van den, Stehmann-Saris, J.C., Deelman, B.G.

Prevalence of apraxie among patients with a first left hemisphere stroke in rehabilitation centres and nursing homes.

Clinical Rehabilitation: 14, 2000, nr. 2, p. p. 130-136

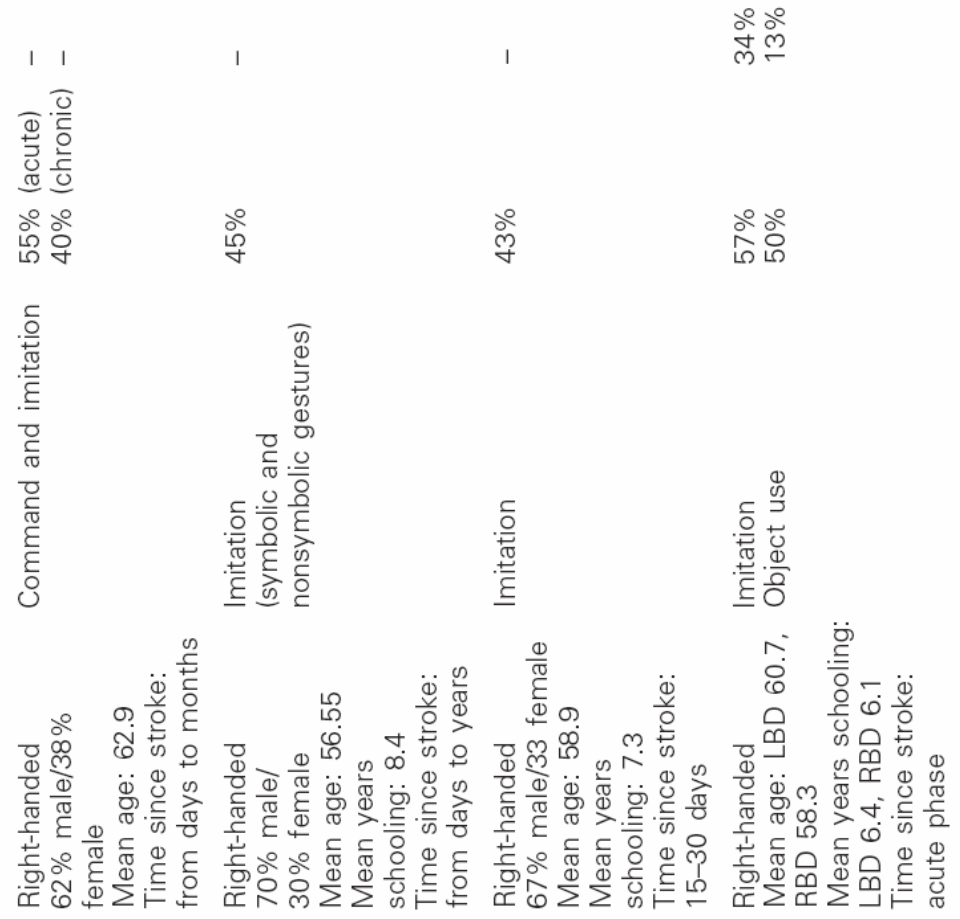

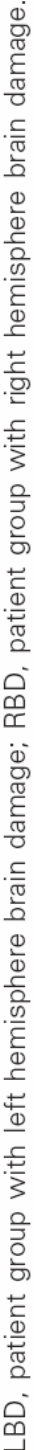

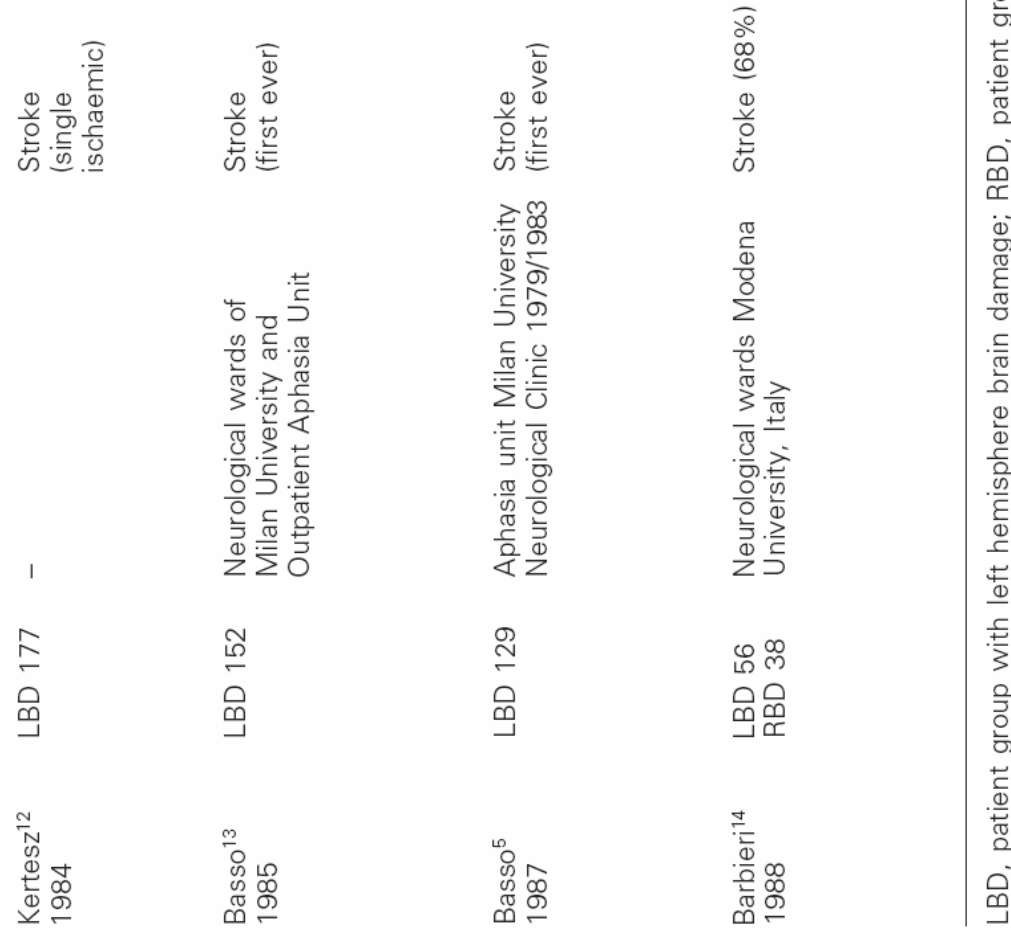


Donkervoort, M., Dekker, J., Ende, E. van den, Stehmann-Saris, J.C., Deelman, B.G.

Prevalence of apraxie among patients with a first left hemisphere stroke in rehabilitation centres and nursing homes.

Clinical Rehabilitation: 14, 2000, nr. 2, p. p. 130-136

Table 2 Patient characteristics

\begin{tabular}{|c|c|c|c|c|c|}
\hline & \multicolumn{2}{|c|}{ Rehabilitation centres } & \multicolumn{2}{|c|}{ Nursing homes } & \multirow[b]{2}{*}{$p$-values } \\
\hline & $n$ & $(\%)$ & $n$ & $(\%)$ & \\
\hline Total & 338 & $(100)$ & 154 & $(100)$ & \\
\hline \multicolumn{6}{|l|}{ Gender $^{a}$} \\
\hline Male & 199 & (60) & 61 & (40) & $p<0.001$ \\
\hline Female & 134 & (40) & 93 & (60) & \\
\hline \multicolumn{6}{|l|}{$\mathrm{Age}^{\mathrm{b}}$} \\
\hline 20-50 years & 72 & (22) & 3 & (2) & \\
\hline $51-70$ years & 200 & (60) & 41 & (27) & \\
\hline 71 and older & 60 & (18) & 106 & (71) & \\
\hline Mean age (SD) & 59.8 & $(11.6)$ & 75.1 & (9.5) & $p<0.01$ \\
\hline \multicolumn{6}{|l|}{ Stroke type } \\
\hline Haemorrhage & 59 & (18) & 29 & (19) & NS \\
\hline Infarction & 245 & (72) & 98 & (64) & \\
\hline Different/unknown & 34 & (10) & 27 & (18) & \\
\hline
\end{tabular}

NS, not significant.

aFor 5 patients in the Rehabilitation Centre group data on gender are missing.

bFor 6 patients in the Rehabilitation Centre group and 4 patients in the Nursing Home group data on age are missing.

Table 3 Prevalence of apraxia

\begin{tabular}{|c|c|c|c|c|c|c|}
\hline & \multicolumn{2}{|c|}{ Apraxia } & \multicolumn{2}{|c|}{ Nonapraxia } & \multicolumn{2}{|c|}{ Uncertain } \\
\hline & $n$ & $(\%)$ & $n$ & (\%) & $n$ & (\%) \\
\hline $\begin{array}{l}\text { Rehabilitation centres } \\
\text { Nursing homes }\end{array}$ & $\begin{array}{l}96 \\
57\end{array}$ & $\begin{array}{l}(28) \\
(37)\end{array}$ & $\begin{array}{r}229 \\
82\end{array}$ & $\begin{array}{l}\text { (68) } \\
\text { (53) }\end{array}$ & $\begin{array}{l}12 \\
15\end{array}$ & $\begin{array}{r}(4) \\
(10)\end{array}$ \\
\hline
\end{tabular}

$p<0.01$.

For 2 patients in the apraxia group and 2 patients in the nonapraxia group data on type of institute are missing.

\section{Clinical messages}

- Studies on the prevalence of apraxia are scarce and concern heterogeneous and selected patient groups.

- Apraxia occurs in about one-third of left hemisphere stroke patients in rehabilitation centres and nursing homes.

- Prevalence of apraxia is not associated with gender, age, or type of stroke.

Fig. 1. Clinical messages 